\title{
Mobile Phones and Children: An Australian Perspective
}

\author{
Niranjala D. Weerakkody \\ School of Communication \& Creative Arts, Deakin University, \\ Geelong, VIC, Australia
}

\author{
ninaw@deakin.edu.au
}

\begin{abstract}
Mobile phones in Australia record one of the world's highest rates of ownership among children under 18. This paper examines issues of mobile phones and Australian children and the various discourses (systematic frames) used in discussing their effects. These are the optimistic (gains); pessimistic (losses, costs or harms); pluralistic (technology per se is neutral but how it is used matters); historical development (importance and skills learnt); futuristic predictions (promises and dangers); current uses (connectivity, convergence and interactivity); and techno-realist view (as a mixed blessing). Taking the Justification View of Technology that sees technological adoption as a gamble and borrowing from Joshua Meyrowitz, it examines how mobile phones have eroded parental power over how, when, where and with whom their children communicate, while at the same time, becoming a 'digital leash' for parents to re-establish their control and an 'umbilical cord' of children to remain connected with parents at all times.
\end{abstract}

Keywords: Mobile phones, technology and discourses, technology and framing, framing, discourses, children and mobile phones, parental power and mobile phones, Australia, digital leash, digital umbilical cord.

\section{Introduction}

"Mum/Dad, Can you pick me up, please?" This is a common telephone call most Australian parents receive from their teenage children sometime late at night on weekends. Australian teenagers of both sexes often go out with friends on Saturday nights from around the age of 15 years and the arrangements for getting together and transport to and from their venues are often made via the teens' mobile phones. These mobiles also give parents at home a link to their children while away from parental supervision and a sense of safety and connectivity. Most of these teens also take part in part-time casual employment, which provides them with a discretionary income to pay for the mobile phones and creating a need to be contactable by employers at short notice when work shifts suddenly become available.

Material published as part of this publication, either on-line or in print, is copyrighted by the Informing Science Institute. Permission to make digital or paper copy of part or all of these works for personal or classroom use is granted without fee provided that the copies are not made or distributed for profit or commercial advantage AND that copies 1) bear this notice in full and 2) give the full citation on the first page. It is permissible to abstract these works so long as credit is given. To copy in all other cases or to republish or to post on a server or to redistribute to lists requires specific permission and payment of a fee. Contact Publisher@InformingScience.org to request redistribution permission.
The rate for mobile phone penetration in Australia is over $92 \%$ or 19 million subscribers reached in less than 20 years of adoption. In comparison, the number of fixed line phones number only 11 million (Chapman, 2006). The nation also records one of the world's highest rates of mobile phone ownership among children under the age of 18. In 2005, mobile phones were owned by about 
80,000 five to nine year-olds, with $50 \%$ of all owners being those between 13 and 15 , and a third between 10 and 13 (O'Riordan, 2005), in a nation with a population a little over 20 million (ABS, 2006). The younger children have their mobiles paid for by their parents and the average monthly bill for a mobile phone for those under 18 is estimated to be about \$50 a month (Allison, 2004).

\section{Purpose of Study}

Even though the social advantages of mobile phones to children and others are many and obvious, there are many different and often valid view points or discourses expressed as to their disadvantages, harms and potential and actual abuses, circulating in Australia and elsewhere. Therefore, it is important to examine all issues related to mobile phones and children of this relatively new technology since limited studies have been so far carried out as to how it impacts, represents and integrates work, family, social relationships and leisure of Australians and their children and to help society and the telecommunications industry to read each other correctly (Australian Mobile Telecommunications Association [AMTA], 2004). It will also help users, society at large and its institutions to examine measures to optimise the advantages and minimise the disadvantages of this useful and ubiquitous technology with its known as well as potential long term adverse effects, in a range of areas such as health, economics, culture, and the politics or power relations between children and adults.

\section{Data Collection Methods}

This paper takes the interpretive and critical theory perspectives (Crotty, 1998) in examining the main discourses (Dicken-Garcia, 1998) and debates about mobile phone use and children in Australia using a textual analysis (qualitative content analysis) of published materials on the discourses of mobile phones and children in Australia. These data sources were identified and the relevant data collected by searching the Mass Media Complete (formerly the Matlon Index) for scholarly literature on the subject; the Factiva database (similar to LexisNexis) for newspaper and trade articles; Google and Google Scholar sites us8ng the keywords, mobile phones, Australia, children etc. Websites of the Australian Bureau of Statistics (ABS), Australian Communications and Media Authority (ACMA), Australian Mobile Telecommunications Association (AMTA), and the Department of Communications, Information Technology and the Arts (DCITA) were also searched on several occasions between 2005 and 2006.

These sources of information were supplemented with depth interviews with Andrew Funston, an Australian academic widely cited for his work on mobile phone use by young people in Australia (Funston \& Hughes, 2006; Funston \& McNeill, 1999) and Ross Monaghan, also an Australian academic, former executive of the Optus telecommunications company and the former Chief Executive Officer (CEO) of AMTA- the group that represents mobile phone operators, manufacturers, dealers and carriers in Australia.

\section{The History of Mobile Phones in Australia}

Ann Moyal (1984) provides a comprehensive history of telecommunications in Australia between 1854 and 1983 covering the introduction and development of the telegraph and telephone services. The first cellular mobile phone service in Australia was introduced in 1987 (Goggin, 2006), and began its life as an 'exclusive' technology, generally affordable and available to the rich, powerful and the 'important' in society. Due to the developments in new technologies such as satellites, and competition between service providers and dealers in a deregulated market since 1996, the mobile phone gradually became more affordable to a larger proportion of the population in Australia. It then changed from being an 'elitist' technology, to an essential 'tool' for many, including youth, teens, the unemployed, and children in their everyday work, family and 
social functions bridging gender, class, age, ethnicity and educational divisions. This is because one does not need to be highly literate, speak a specific language, an adult or specially trained in order to use one, unlike the Internet or computers (A. Funston, personal comm.unication 14 November, 2006; Goggin, 2006).

Australia is among the leaders in the adoption of mobile phones which is well suited to its culture, geography and demographic distribution as a large island continent with a relatively small population. The country is also unique because its population is concentrated mainly around the five state capitals of Sydney, Melbourne, Brisbane, Adelaide and Perth, while the rest of the continent is sparsely populated. Therefore, in comparison to landline phones, setting up the infrastructure for mobile phone services for a larger number of subscribers was relatively cheaper-especially in metropolitan areas (Weerakkody, 2007a). Australia is also a developed nation with an educated and affluent population with a penchant for new technologies, as shown with their high adoption and fast diffusion rates for television, CD and DVD players, home computers and the Internet (A. Funston, personal communication 14 November 2006; Weerakkody, 2007a). Australia using a uniform GSM (Global System for Mobiles) network nationwide also helped the speedy diffusion of digital mobile phones (R. Monaghan, personal communication., $29^{\text {th }}$ November, 2006).

\section{Mobile Phones and Children in Australia}

According to Nielsen/Net Ratings (2005), 50\% of Australian children (under the age of 18) own a mobile phone. Camera phone use among the same group had rapidly increased from $2 \%$ in 2003 to $52 \%$ in 2005 . In $2003,50 \%$ of parents in metropolitan areas had paid their children's mobile phone costs, with the figure increasing to $61 \%$ in 2005. In a Nielsen Panorama survey in 1999 (cited in Funston \& McNeill, 1999) the most often cited reasons for Australian children getting a mobile phone were, for easier contact with friends (50\%), contact with family (48\%), for security when out alone (45\%), parents wanting to keep in touch (29\%), given as a present (23\%), caller privacy (11\%), easy contact with employer (of part time jobs) (10\%), job searching (9\%), got it cheap from a friend (9\%), and to feel good about themselves by having one (5\%). In terms of the most important reason to get one, the most cited was security $(21 \%)$ and easier contact with friends $(15 \%)$. Accordingly, fifty eight percent $(58 \%)$ felt more secure with a mobile but it was higher for females with 75\% and males with 38\%. However, Funston and Hughes (2006) found that young people preferred face-to-face contact with family and friends far ahead of communication via the mobile phone (or the internet).

Children under 16 are not issued with a prepaid mobile phone handset or SIM card by dealers in their own names. Therefore, they need to do so under a parent's name for both. They may buy a used handset from a friend, or a receive hand-me-down from an older sibling or parent, who may have upgraded theirs. Children under 18 years of age need to get a parent to sign for their handset or mobile phone contract, even if they may pay for it including monthly bills.

\section{Paying Mobile Phone Bills}

Parents generally pay the mobile costs of children who are not old enough to or do not have part time jobs. The most problematic area with respect to children (mainly teenagers) and mobile phones in Australia appears to be that of unexpectedly high mobile phone bills (in extreme cases up to $\$ 5000$ in accumulated charges) incurred by about $10 \%$ of users, which parents end up paying, or the teens themselves pay with a loan from a parent or other adult, which results in anxiety, depression and other problems (Funston \& McNeill, 1999; A. Funston, personal communication, 14 the November 2006; R. Monaghan, personal communication, $29^{\text {th }}$ November, 2006). Anecdotal evidence suggests that most teens rack up higher monthly bills than expected, due to getting 'carried away' during weekends with too many calls sent unnecessarily or downloading games or ring tones on impulse. Sending Multimedia Messaging Service (MMS) messages using mobile 
phones with cameras for still and video photography, also incur much higher call charges but teen users may not realise it until they receive their bills.

\section{The Common Pitfalls}

Due to aggressive marketing and confusing advertising that promises a 'free' handset or 'low' monthly charges and not reading the contract or not understanding its clauses about the specific terms, conditions, and charges for various services (generally written in legal or business jargon instead of plain language), many young people find themselves faced with high bills they cannot afford to pay. The availability of 'premium services' such as wall papers, ring tones, music and games downloads, sports scores, and sports highlights may be enticing, but the teen consumers may not realise that they are provided on subscription involving on-going charges and are difficult to discontinue (ACMASphere, 2006). Hoping to alleviate this problem, the Australian Communications and Media Authority (ACMA) proposes a Mobile Premium Services Self-Regulatory Scheme hoping to protect those who access a premium service by requesting service providers to make available "more information about the nature of services, costs, terms and conditions" to subscribers before their first use (ACMASphere, 2006, 3).

The teens and/or their parents faced with exorbitant mobile bills are often unaware of how to resolve them or whom to contact in case of a dispute with a mobile phone company or dealer, such as the office of the Telecommunications Industry Ombudsman (TIO) (A. Funston, personal communication, $14^{\text {th }}$ November, 2006; R. Monaghan, personal communication, $29^{\text {th }}$ November, 2006). Many also find that their contract has locked them for 18-24 months, which they cannot discontinue without a costly penalty even if the set was broken and un-repairable or better models or deals become available with the same company. These subscribers had not realised that they have to pay for accessing and leaving voice mail messages even if the mailbox is provided free as advertised; that the 'free calls' allowed each month under the plan may be used up fast when timed as 30 second segments which means, even one second in excess will billed as an additional 30-second segment; that the cost of the handset is included in a mobile phone plan in a contract which says 'Free hand set'; and that pre-paid calls with a phone card (an option to control costs) charge more than those on a plan or contract with the card's credit expiring after 3 months if unused.

ACMA's Chairman Chris Chapman (2006) admits that "transparency of the costs and terms and conditions of premium services has continued to be major source of complaints for the TIO"... "sloppy, even unacceptable, practices by some providers of content have led to financial harm to consumers" which he thinks harms the industry's reputation and destroys consumer confidence about mobile or m-commerce (p. 5).

\section{The Most Affected}

Funston and McNeill (1999) found that those from non-English speaking homes and those on government payments -received by $13 \%$ of Australian homes which are on low incomes (Croucher, 2006), were more likely to face problems with excessive bills than others, probably due to their parents' inability to understand the contracts and inexperience with the procedures. As a result, in recent times, the Australian Communications and Media Authority (ACMA, 2006) has provided a toolkit on its website, for teenage users to understand the system and lists a set of questions to ask when purchasing a mobile phone (ACMASphere, 2006). Consumer Affairs Victoria, a state government entity has articles in free youth-oriented magazines such as the Stuff Magazine with advice for young people ("Totally Mobile," 2006). However, it is not clear as to how many parents and teens know about or use these resources before purchasing a mobile phone. At the same time, research has shown that many young people and teens use the mobile in an exercise of responsible and essential usage; developing financial and time management skills; 
and learn to use mobiles to better coordinate their everyday social and other activities (Funston \& MacNeill, 1999).

\section{Public Debates on Mobile Phones and Children}

However, most legal, administrative, public and political debates initiated or contributed to by politicians, lobbyists, interest groups and even the media about mobile phones in Australia appear to be not about these mobile phone-related financial problems but about the potential 'harms' or 'losses' to children from inappropriate mobile phone content or anti-social behaviour such as bullying, cheating at exams or pedophilia. They also argue for the need to censor or control these behaviours via criminal legislation to punish or deter offenders and for installing parental control systems on the mobile phones to 'protect' children from these 'villains' (Ace*Comm, 2005; "Australian Government to Censor," 2006; Handsley, Frost \& Biggins, 2004; Miletic, 2006; Osbourne, 2006; Richardson, 2006; Spiked-Debate, 2006). No real efforts appear to be made by these same politicians, lobbyists, interest groups or the media about addressing the real issue of excessive and exorbitant mobile phone bills affecting the mostly teenage users via regulation of the Telcos and their dealers.

The factors responsible for these mobile cost blowouts are often linked to inflexible mobile phone contracts, confusing and aggressive marketing strategies specifically aimed at the teenage market, inadequate information provided to prospective subscribers, hard to understand contracts, and the lack of education for dealers, the public and young people about potential 'pit falls' and the responsible management of their mobile phone use and expenditure (A. Funston, personal commumication, $14^{\text {th }}$ November, 2006; R. Monaghan, personal communication, $29^{\text {th }}$ November, 2006).

\section{Theoretical Frameworks}

The paper takes the Justification Model of Technology (Hamelink, 1988) that sees the adoption of a new technology and its policy making and regulation as a form of 'social gambling'. This is because, we do not know everything about a new technology and its capabilities until it has been in existence and used in society for many years or if the technology will be used at all by the end users once adopted. Their uses and applications may also change from time to time without warning or the technology can be used in unexpected ways once adopted, such as the use of the Internet by underage children to download pornography. In other words, adopting any new technology by definition involves risk or a 'gamble'.

\section{The Main Views of New Technologies}

Hirschheim (1985) presents three main views on the social impact of new technologies. They are the optimistic view, which takes the utopian approach of technology being all positive and is themed as 'leading to progress' while providing 'gains' to human kind. It is the view taken by theorists such as Marshall McLuhan (1969). In contrast, the pessimistic view taken by those such as Beniger (1986) sees technologies as creating harms and increasing the power and control of those with power and authority. Foucault (1977) too takes the same view and links technologies to the panoptic control or surveillance of those on the 'periphery' (the less powerful or powerless) by those at the 'centre' (those holding power). Such control is seen as leading to abuses, misuses and oppression. The pluralist view of technology on the other hand sees a technology as neutral in themselves such as a building block or brick, but as a structure, how it is used depends on the wishes and desires of the designers and controllers of the technology, which leads to positive, negative or neutral outcomes depending on how they are used (Burns, 1981). The above views are the three main discourses of technology and the most commonly used ones in society today. 


\section{Discourses of Technologies}

A discourse refers to how a subject or topic gets 'talked about' in society at a given time and location in everyday conversations or in the media. They are shaped by the culture and in turn shape culture (Dicken-Garcia, 1998). Any given subject or topic can be discussed using several different discourses or in different ways, all of which can be valid. But the discourses used in a discussion or debate are shaped and dominated by the agendas, interests, viewpoints, ideologies, subjectivity and subject position (of being dominant/ privileged /powerful or oppressed/marginalised /powerless in society) of each of the individuals or groups participating in it. This explains why any topic or subject can be debated or discussed using several different discourses and why some discourses dominate while more or equally valid, urgent or legitimate others get sidelined or ignored. For example, the perceived 'harms' of mobile phone content of apparent concern to middle and upper class parents in Australia, dominate over the issue of high mobile costs, which Funston and McNeill (1999) found to negatively affect the less affluent and minority teenagers more than others.

The additional discourses applied by Dicken-Garcia (1998) to the internet and adapted here for the mobile telephone include historical development of mobile phones, emphasising the skills learnt and their importance such as to bridge the 'digital divide' between the rich and poor individuals, groups, and nations; and the discourses of futuristic predictions relating to promises and dangers for the future. Current uses as a discourse, discusses the importance of mobile phones today such as connectivity, convergence, interactivity and the realisation of the global village (McLuhan, 1969). The techno-realist view takes the middle ground and sees mobile phones as a mixed blessing.

\section{Discourses and their Framing}

Framing or the frameworks used in a discourse involve selection (of certain aspects) and salience (importance) of the aspects included in the discourse. Frames diagnose (identify the sources causing the problem), evaluate (make moral judgements about causal agents and their effects), prescribe (suggest remedies, offer and justify treatments) and predict (their likely effects) for an issue or subject under discussion (Entman, 1993; Solomon, 1992). In simple terms, one can 'frame' a glass that contains water as 'half full' or 'half empty'. Each discourse is shaped by the outlook of the person using the frame and in turn shapes how others are influenced to look at the situation (Dicken-Garcia, 1998). Framing is the basis of advertising, marketing and political as well as public relations messages and campaigns. Media messages are framed -either consciously or otherwise, by journalists and other creators of messages, in particular ways and carrying particular discourses. They tell us "what to think about and how to think about them". In journalism, framing is linked to the 'angle' used in a news story and choosing a 'lead' for it. The lead controls how one tells the rest of the story and what headlines may be used (Dicken-Garcia, 1998).

\section{The Mobile Phone as 'Villain'}

For example, the mobile phone is framed as the 'villain', in cyber-bullying in a newspaper article by Miletic (2006; p. 6), headlined "Technological trauma: Cyber bullies more powerful than schoolyard thugs", taking the 'angle' or discourse of 'harms'. The diagnosis of this frame is that: since bullies get to use text messages and mobile phone photos and videos that can be uploaded to social networks such as YouTube and MySpace, anonymously and virtually for anyone, anywhere to see, bullying has become a 24-hour 7-day possibility that goes far beyond school boundaries. The evaluation is that this causes trauma, increases the humiliation and victimisation of those targeted than real life bullying, leading to anxiety, depression, truancy, self-harm, eating disorders or even suicide, as the humiliation can reach a wider audience and go on for a longer period of time than when carried out face-to-face in the 'real' world. It prescribes harsh punish- 
ments to perpetrators such as expulsion citing the King's School in Sydney, and including cyber bullying to school anti-bullying policies drafted in consultation with students, citing Melbourne's Methodist Ladies College as an example. It predicts that since cyber bullying leaves records on computer hard discs, culprits may be caught and all students will understand the inappropriateness of cyber bulling and that redress and repercussions can be expected in future situations.

\section{Frames as Rhetorical Weapons}

Framing of discourses is central to political debates where discourses serve as rhetorical weapons created and used by political and economic elites to advance their interests and ideologies. But alternative frames can tip the balance of policy debates and public opinion (Kinder \& Sanders, 1996). By framing a discourse in a particular manner or direction, a sender of a message can place 'blinkers' or 'blinders' on the receiver guiding their view or attention in a particular direction and away from any alternative viewpoints. This guides the receiver to think only about the sender-highlighted aspects of an issue under consideration (Weerakkody, 1999). In other words, different discourses and frames can contribute towards creating specific connotations (implied meanings) for the receivers of such messages and /or make their minds unconsciously stick to a particular paradigm (a pattern or the way of looking at something).

For example, Senator Helen Coonan- the then Federal Minister for Communications, Information Technology and the Arts in Australia announced plans to introduce legislation to "restrict (children's) access to inappropriate or harmful content" on "emergent content services" that included 3G mobile phones which are able to receive TV and Pay TV broadcasts ("Australian Government censors," 2006). Her announcement followed the controversy related to the airing of the "Turkey slapping incident" on the Big Brother 6 reality TV show in 2006, where two male contestants sexually harassed a female contestant, which was streamed live on Channel 10 TV's 24 hour webcasts- a subscription-only service, during the early hours of the morning on July 1, 2006 ("Big Brother Australia," 2006; p. 18). This announcement can be interpreted as an attempt at political point-scoring by the government and the Minister. This also carries out an agenda setting function (McCombs \& Shaw, 1972) by highlighting the potential for children accessing porn on mobiles and making it an issue for parents.

According to the same news item, a report submitted to the minister had suggested that internet access via mobile phones be restricted to customers over 18 unless minors have permission from parents or guardians ("Australian Government censors," 2006). Interestingly, under current Australian law, a minor cannot sign up for an account with an Internet Service Provider (ISP) but is able to access WAP (Wireless Access Protocol) internet services without restriction. However, wireless internet services on mobiles are unlikely to be subscribed to by the average minor due to its current cost but this was not pointed out in the news item, which is an exclusion of alternative discourses and frames from the discussion.

\section{Pluralist Discourse on Mobile Phones}

On the subject of adult material on mobile phones being accessible to children, Andrew Funston thinks that "porn is a major driver of selling the internet to the world. I can't see why it can't be the case with mobile phones... and children can find them (inappropriate content) solicited (by content creators) or found themselves. (The government) regulation is not looking into it much as they are more concerned about building telecommunications markets because the (telecommunications) companies have a lot of clout. The government does a lot to censor what goes on in a film festival but not about (other) media content..." However, he thinks that "mobile phones will be a way young people will be enticed into anti-social behaviour" as seen with the "Werribee Kings' incident of June 2006, where two school boys contacted a 17 year-old girl (with a mild development delay) on the internet, arranged to meet her using mobile phones and a gang of 12 
boys then sexually and physically assaulted her while taking videos using mobile phone cameras. The footage was made into a DVD and sold for \$5 and also uploaded on YouTube ("Melbourne teenage DVD controversy," 2006). Andrew saw such teens as "callous and hateful young men who had not been well parented or supervised" and who "had the technology in hand to make what they did even worse" (A, Funston, personal communication, $14^{\text {th }}$ November, 2006), evoking the pluralist view.

Presenting an alternative frame, Andrew Funston argues that "The bigger issue is not whether the technology is dangerous... but about how we educate ourselves as a community on ways of not patrolling information but empowering them to get the information they want and not suffer information they don't want. So the idea of home-based screening is important for families to learn how to talk among themselves about what is suitable and the damage done to people in the making of it (adult content). Self-serving technology, education systems and public information should be available" (A, Funston, personal communication, $14^{\text {th }}$ November, 2006). Unfortunately, such views and alternative frames and discourses do not get the media exposure enjoyed by politicians, lobbyists, Telcos, advertisers and journalists.

Ross Monaghan points out that "In Australia, sex sells...in advertisements, on the (web) page of mobile phone companies... the very first thing you see is 'download the hot babe' and it's going to cost you two dollars ... With a pre-paid mobile, they (content or service providers) don't know if it is a 11 year old or 60 year old (downloading)... (However), the government makes sure there is no hard core porn out there. ..The commercial side of mobile phones means porn available free will be limited. ..They have relationship services like 'texting a hot babe' (chat lines similar to the 1-900 phone calls). If you read the fine print those text messages are ...expensive ...3, 4, 5 dollars to send texts. Sometimes these messages may be sent daily and some can get caught out by these services" (R. Monaghan, personal communication, $29^{\text {th }}$ November, 2006). In other words, there may be adults as well as teens who may end up racking up mobile phone bills and facing economic hardship in the future due to these services, just as with the regular mobile phone functions or 1-900 numbers for sex chats on landline phones.

However, Ross Monaghan also thinks giving a mobile phone to a child early in life could teach a valuable lesson about money. “...So there isn't so much of a novelty factor... when they eventually get one (of their own)... they are not going to go berserk with it. ... Just don't give them a phone... Sit down with them and explain the costs, the dangers, the reasons why they have the phone" (AAP. 2006).

\section{Strategies of Framing}

Framing uses various strategies (Dicken -Garcia, 1998) such as adjectives (describing words such as 'empowering'); metaphors or understanding one thing in terms of another (Lakoff \& Johnson, 1980, p. 5) (such as the mobile phone as a 'digital leash' of tying teens to their parents for control or an 'umbilical cord' tying parents to their children providing 'sustenance', with both parties contactable at all times); analogies (drawing similarities between two things such as comparing the changes brought by driving a car and mobile phones for teenagers, to express their freedom and independence from adult supervision (Levinson, 2004).

Frames can also use euphemisms- a strategy of using a neutral or 'fancy' term to cover up an unpleasant reality (Planalp, 1998, p. 69)- such as using 'child protection' to hide the fact that the policy involves surveillance and control of teenagers and their movements using GPS (Global Positioning Systems) and other 'spying products' (Spiked-debate, 2006) or the use of the term 'premium services' to downplay the fact that they are expensive and provided by subscription; and disphemisms - the opposite of euphemisms where exaggerated terms are used to make something sound more unpleasant than it really is (Planalp, 1998, p. 69)- such as those advocating sur- 
veillance of mobile phones arguing about the 'risks' of 'child abuse' and its detractors referring to these arguments as 'manufactured hysteria' (Spiked-debate, 2006). Those seeking more controls on mobile phones by parents on children, argue that 'pedophiles' may use the technology to lure children. They in turn are accused of creating 'moral panics' arguing that pedophiles are unlikely to use mobile phones which are more easily traced than the internet, often used by pedophiles.

\section{The Main Discourses of Mobile Phones}

The main discourses about mobile phones and children, commonly encountered today in Australia relate to their actual or potential 'harms'; 'losses'; 'mobile phones today' with respect to connectivity, convergence, and interactivity; and using mobile phones for surveillance and control of teens. The following is a critical examination of these discourses.

\section{Discourses of 'Harms' and the Mobile Phone}

Levinson (2004) points out that each new technology becomes a 'villain' when first adopted and remains so till the next one comes along, making the old one legitimate. He cites the example of movie viewing seen in 1910 as "destroying the moral backbone of the future as children spend their afternoons (at the cinema)", making the earlier villain of the 'bawdy' theatre a legitimate medium (pp. 86-87).

Spiked-debate (2006) describes the 'harms' posed by mobile phones to children as the 3 Cs- Contact (by pedophiles), Content (illegal or harmful materials) and Commercialism (risk of spending too much money or buying unsuitable goods). Other less debated fears involve health risks due to Electro Magnetic Radiation or EMR from handsets. A longitudinal study of 300 children over a period of three years is underway in Melbourne to study the effects of EMR even though several earlier studies worldwide have indicated no harm-either to children or adults (Allison, 2004). However, Andrew Funston argues that the effects of such health hazards will take up to 30 or so years to be observable or research findings to be conclusive as seen with the poisoning of workers in an asbestos factory in Australia. "Sperm motility affected by mobile phones (kept in trouser pockets)... (mobiles) may cause a particular form of brain tumour ...or create temporary loss of intellectual capacity... Holding a device with EMR close to your head and generating heat, plastic etc .. Something that might have negative effects in 30 years may not affect us adults today but a 10 year old child today will be, in 30 years" (A. Funston, personal communication, $14^{\text {th }}$ November 2006). For this reason, Andrew has not purchased a mobile phone for his 10 year-old son.

Even though mobile phones are no longer an "exclusive " technology and affordable to the majority of the population, its 'status symbol' function still appears to be in existence. Many successful men are known to place their latest model mobiles on the table at meetings, restaurants, or in bars to impress onlookers. Today, the BlackBerry -an expensive mobile phone with almost computerlike functions is a status symbol for professional men. Some Hollywood celebrities have spent up to US $\$ 80,000$ to buy ones embedded with precious stones. Even teens keep updating their mobiles and buy expensive and unnecessary accessories such as covers, ring tones and wall paper to stand out from the crowd.

Mobile phone designers carry out anthropological research using field studies, participant observation and depth interviews with people from different cultures to gauge their tastes and habits and understand culture-specific tastes, uses, practices or functions and the basic human motivations to do so, in order to exploit even the poorest person's need to "show the rest of the world they have arrived" by buying the best possible model (Barker, 2006, p. 2). Andrew Funston refers to this phenomenon as "Capitalist or product fetishes" (A. Funston, personal communication, $14^{\text {th }}$ November, 2006). 


\section{Discourses of 'Loss' and Mobile Phones}

Some Australian educators and politicians lament that text messaging is destroying children's writing, and results in their losing their spelling and grammar skills. The limited number of characters allowed in a text message and the convenience and practicality of sticking to fewer characters and words has given rise to a new text messaging 'shorthand' such as 'Satdy' (Saturday), 'WOTEvr NXT' (whatever next), 'GTSY' (good to see you) and the use of '4' (for), r u (are you) etc. (Topsfield, 2006). Some teachers have warned students not to use such spelling at examinations. They complain that many students have lost the art of cursive writing (running script) due to word processing and many only write in block letters and fail to learn spelling, grammar and punctuations correctly due to the availability of spell checks and grammatik. They fear this could lead to future generations failing to write or read handwritten scripts written in cursive in historical documents (Pressler, 2006).

However, discourses of children losing their writing skills due to a new technology are not new. When the pencil with an eraser attached to it was introduced, some argued that it would make children become careless when writing (Marvin, 1988) as they knew they can erase a mistake and re-write it. When ball point pens were introduced, children were discouraged and even forbidden in schools to use them on the argument that they make a person's handwriting 'ugly'. The then Federal Minister of Education in Australia -Julie Bishop also criticised school curricula that included English units on 'Text messaging' where students were asked to discuss issues associated with text messaging and learn to translate and write SMS texts, as distracting them from learning communication skills related to the job market and further education (Topsfield, 2006).

I would argue that languages, writing styles and rules are dynamic, culture and time-based, and adapt to changes in society and the technological environment and therefore need to be discussed within that context. Most often filling forms by hand requires using block letters instead of cursive. Since this generation is far more techno-savvy than earlier ones, they will develop and need different skills and literacies to those of their parents. Therefore, I would argue that adults today appear to be attempting to privilege and impose their paradigm of literacy, by setting it up as the 'norm' or the 'ideal' for the next generation. They also tend to forget that our generation is also different to that of our parents and faced the same criticisms, fears and discourses of 'loss' during our formative years, such as with ball point pens.

As for hand writing, one should remember that our first form of writing was hieroglyphics and for example, letters of the early Sinhalese script (of Sri Lanka) were square in shape due to being written on stone tablets. With the introduction of 'Ola' or dried palm leaves as the medium, the letters changed their shape to round, to avoid tearing the Ola leaf when drawing straight lines with a sharp instrument which the square letters tended to do (Wickremage \& Weerakkody, 1986). As for failing to read historical documents, I would argue that the affected generation would probably develop computer software or other system to decipher them, if it becomes necessary or commercially lucrative or as with reading historical documents such as the Dead Sea Scrolls or those written in dead languages such as Sanskrit or Latin, the field will become the realm of specialists.

Andrew Funston thinks that "text messaging is not about crunching the English language but creatively adding to the language... Imaginations will be tickled by the enormous creative work gained into making (the messages) attractive. We will be constantly asked to shift paradigms in our thinking... But text messages are so elliptical, sparse and open to misunderstanding (due to the absence of non-verbal aspects of communication such as pitch and tone and phatic communication such as small talk)... Even though it gives power to young people and a strong speaking position... it could lose them the opportunity to talk expansively.... They need the full range of (language) ability, a balance and a range of skills" (A. Funston, personal communication, $14^{\text {th }}$ 
November 2006). Pressler (2006) sees the loss of handwriting as a cognitive opportunity missed as the neurological process that directs thought through fingers, into written symbols is highly sophisticated (p.18). I would argue that typing and texting also involve such a neurological process, even though different to hand writing. At the same time, today most if not all successful creative writers such as novelists, word process their manuscripts instead of hand writing them, apparently with no 'loss' to the world and definitely more conveniently.

At the same time, we should remember that the new technology of the telegraph gave rise to the new 'writing style' of the Morse Code while the typewrite gave rise to 'shorthand'. However these 'languages' were developed by adult professionals while text message styles were developed by the mainly younger users themselves and diffused through widespread use and adoption of its own conventions and followed by all users.

\section{Discourses of Parental Control and Changes in Power Relations}

In the past when using landline phones at home, its use was a site of conflict and control for parents as gatekeepers (White, 1950) over its use by the teenage children as to who they communicate with, for how long and when. However, with mobiles, teens are able to call any one, any time, anywhere since mobile phone use -especially with texts, can be very private, which they often pay for. Funston \& Hughes (2006) found that many children under the age of 18 from separated or divorced families found it useful when contacting or staying in touch with their nonresident parents when the parents are in conflict or they have to worry about the feelings of their resident parent when contacting the other. These teens will also find that they can circumvent the gatekeeping of the landline phone by one parent or their new partners, when contacting the other, and can do so in private with mobiles. The current divorce rate of Australia is at $48 \%$, similar to other western industrialised countries and 1.1 million children under 18 are estimated to live with just one parent in separated families, with $85 \%$ of them living with their mothers. Mobile phones help these children to maintain contact with fathers living too far away or in conflict with the mother (Funston \& Hughes, 2006).

The phenomenon of mobile phones eroding parental power fits in with Joshua Meyrowitz (1985), who theorised for television but which could be extended to the internet and the mobile phone. He argued that electronic media have allowed children (as well as women and followers who are less powerful than adults, men and leaders respectively) to access hitherto restricted information. For example, kids can now access adult information without parental (or power holders') supervision, intervention or knowledge via the media such as the Internet. This is in contrast to the times before the advent of media technologies, when parents decided when to make adult information available to children. Assuming that information (and the ability to communicate) is power, he argues that this situation reduces the power imbalance between children and adults (just as between women and men and leaders and followers) (Meyrowitz, 1985). However, as with any power struggle, this situation is a 'tug-o-war' for the parties concerned-in this case, parents and teens.

\section{The Tug-o-War for Control}

One of the issues related to mobile phone use in Australia is its potential use in the surveillance of users. Global Positioning Systems (GPS) installed in mobile phones are promising parents to know the locations of their kids at all times (Handsley et al., 2004). However, the same authors argue that it provides pedophiles and bullies the location of the kid, outweighing its benefits. They also discuss the use of filtering controls for 'inappropriate' mobile phone content similar to those used on the Internet. However, the efficacy of such software is doubtful considering the failure of spam control software used for emails or filters for internet content. 
Accordingly John Carr - Chairman of UK's Children's Charities Coalition, "In the so called 'child protection' market, many spying products are being heavily promoted" (cited in Spikeddebate, 2006). Andrew Funston sees surveillance technologies as unnecessary and a ruse for companies to sell another product (A. Funston, personal communication, $14^{\text {th }}$ November 2006).

Frank Furedi, author of Paranoid parenting describes the dilemma faced with mobile phones as "young people's aspirations to independence run counter to parents' strategies of safety and control" (cited in Spiked-debate, 2006). Levinson (2004) describes the telephone and the teenager as a 'technological fable' where a device long sought after, which once possessed had quite the reverse of the benefits expected (p.85). Even though teens today can own their mobiles and pay for them and be 'free' of parental control to use it, they are expected to have the mobile phone 'switched on' at all times to be contactable by parents and can no longer 'walk away' (from parents). Having the phone switched off or not answering the phone (when they can see who is calling) has now become a point of conflict for parents and teens. In other words, the mobile phone has reversed the trend of new media empowering and emancipating teenagers by extending the 'sinews of family' creating a 'mobile hearth' (and home) with continuous familial informationsharing making teens more accountable to parents about their whereabouts (p.89). Levinson (2004) sees the mobile phone as "an excellent assistant on both sides of the transformational process- the little child before and the adult after- just not the middle, at the point of transformation, the teenage turning point" (p. 90).

Telstra's TicTalk plan is offering a $2 \mathrm{G}$ mobile phone aimed at kids between the ages of 6 and 13 years of age, which can be programmed by parents by going on its website to allow the child to receive from and dial only certain numbers, have it only set up for certain text messages, games, or ring tones and has an organiser for their activities, giving parents a sense of control and child safety from "inappropriate content and contact" (Stratel, 2006). I see this situation as a marketing ploy by Telstra to sell off equipment from an outdated (2G) range as $3 \mathrm{G}$ has already been established in the market. Ross Monaghan points out that these controls can be set up on any mobile phone by parents of younger children if they wish to and the procedure is detailed in the user manuals (R. Monaghan, personal communication, November $29^{\text {th }} 2006$ ). In other words, many discourses appear to be presented by the mobile and ancillary industries to widen and create their markets. However, Optus, the second largest telecommunication company in Australia "does not have any mobile products specifically to target children younger than 16 years" (AAP, 2006).

\section{Discourses of Convergence, Interactivity and Connectivity}

Mobile phones are excellent examples of convergence, interactivity and connectivity provided by new communication media that can bind time and space.

Convergence refers to 'coming together' of previously separate technologies, industries and functions in the same equipment. Interactivity is the ability of customers or end users of mobile phones to choose the timing and location to send or receive messages as well as to create and choose the content they send and receive (Weerakkody, 2007b). The small screen of the mobile phone connected to a still and video camera has the capacity to send and receive messages combining voice, text and multimedia, emails, faxes; surf the internet, receive audio and video content from service providers such as music, Pay TV, and free-to air TV; use it as an alarm/clock, personal telephone directory, note pad, answering machine, video game console, vote for a reality TV contestants; donate money to a charity (as seen during the Tsunami Appeal after Dec. 2004) or buy items such as soft drinks from a vending machine, using their mobile phone credits / account etc. In the case of the BlackBerry, the functions of a computer are also included with a Qwerty keyboard and an operating system to run business applications. These indicate examples of convergence and interactivity 
This convergence and especially their interactivity make mobile phones different to other contemporary technologies such as TV, Pay TV and the Internet and more problematic or of concern to parents, as the others are more one-way and non-interactive technologies (Levinson, 2004; 88). The mobile phone's multimedia functions (or convergence) such as cameras lead to privacy abuse, criminal and anti-social activity with the young more likely to be the victims as well as perpetrators (Funston \& Hughes, 2006, p. 78). Due to this convergence and interactivity, Thomas (2006; p. 1) calls mobile phones as every day mobile 'devices' rather than 'phones' and sees them as cultural artefacts, adopted as well as adapted by their users.

\section{The Digital 'Leash / Umbilical Cord'}

Connectivity of the mobile phone has produced interesting effects on both teens and their parents, with it becoming a double edged sword. It serves as an 'electronic or digital leash' for teens, expected to be contactable by their parents at all times who want to know where they are and if they are safe. At the same time, mobiles have become an 'umbilical cord' linking kids to parents, which parents seem unable to 'cast off', even if they wished to. Recently, a senior professional woman chairing an important meeting excused herself to answer her mobile around mid-day saying "Sorry, I have to take this call. It is my 13 year-old daughter and this is her umbilical cord". In other words, a mother or father can not expect to be left alone at work, as their children can now call them anytime to ask for lifts, "What is for dinner?", or say "I forgot to take the house key (and can't get in), so can you come home please?" when a parent is working late, restricting their freedom. (Very few Australian homes have household helpers and many families have two working parents or are single-parent households, with no other adults such as grandparents living with them.)

'Luke', a father of two sons aged 18 and 20 living at home, summed up his situation as being unable to go out on weekends because he has to be 'on call' in case one of them needed a lift home after an evening out in the town. Luke often drops off his sons and their friends in town for their outings as well. Due to the absence of public transport during late hours and the high cost of taxis to come home in the suburbs from the city centre, the sons need transport as they cannot drive after consuming alcohol even if they have their own vehicles. Australian culture is also such that young people going out on their own on weekends and consuming alcohol in social settings is quite common and acceptable. Luke describes himself as "working for the fire brigade" waiting to 'run' when the call comes.

Australian teens and youth today labelled 'Echo Boomers', 'Generation Y' or the 'Millennium Generation' (born between 1982 and 1995) (Reikert, 2006; 6) remain home much longer than earlier generations due to going for higher education, thereafter repaying student loans, and the rising cost of home ownership in the last decade limiting their ability to buy their own homes. Some remain home with their doting 'Baby Boomer' parents to save the down payment on a house. So Luke and others like him can expect to live with this 'umbilical cord' intact for a few more years. In other words, the mobile that was supposed to keep children and teens 'freer' and 'safer' when out of the home, had transferred part of that responsibility on to the parents for much longer than before in a contradiction of the mobile phone. At the same time, this is not a surprise as contradictions are the hallmark of the postmodern society we live in today.

\section{Conclusion}

The mobile phone in egalitarian Australian society has well established itself as a technology which has bridged the social divide in terms of age, gender, education, and socio-economic class, just as elsewhere (Geser, 2004). However, mobile phone access in terms of the infrastructure can still be unequal between metropolitan and rural areas and among the very poor and others, the latter only able to use it for essential telephone functions (A. Funston, personal communication, 
14 November, 2006). The higher end models of mobile phones and their expensive and specialised functions such as the BlackBerry, also favour those who are more affluent and still serve as a status symbol.

The future mobile phones can be expected to become further miniaturised, converged and interactive with each new development and model. For example, the iPhone from Apple announced in January 2007 will further increase convergence as it combines the iPod, the mobile phone and the Internet. It was introduced to the US market in June 2007 and will be released in Australia and Asia in 2008 (Miller, 2007).

Ross Monaghan sees mobile phones being used by young people to access youth social networks such as MySpace in the foreseeable future. He does not see the small screen as suitable for viewing full length movies (R. Monaghan, personal communication, $29^{\text {th }}$ November, 2006; Weerakkody, 2007b). Mobile phones have already overtaken landline phones in numbers and may make the latter obsolete just as mobiles are gradually making public phones little used and cost ineffective to maintain. Hybrid phones that can serve both mobile and land line functions have been in the market for a while. Mobile phones are also increasingly used by educational institutions to send messages such as examination results to students, acknowledging their popularity with young people. Barker (2006) sees the future mobiles developing culture-specific functions to suit various local conditions and introduction of flexible components such as 'electronic paper'. At the same time, as Hamelink (1988) explained, we have yet to see all what the mobile phone can do and what people will do with it.

\section{Future Directions for Research}

Just as Goggin (2006), who traced the history of mobile phones in Australia, the author too found it difficult to locate up-to-date official data and statistics for the technology, partly because they change so rapidly. Scholarly research on mobile phones were also few. The subject of Australian telecommunications, appear to be most often researched in terms of policy (Goggin \& Newell, 2000; Langtry, 1998) and mobile phones and relationships (Funston \& Hughes, 2006; Horstmanshof \& Power, 2005). The author also found that telecommunications companies carry out research on issues of interest to them and organisations such as ACMA were commissioning research that examine media use ("Media and society research project initiated," 2006) and other subjects within the frames of reference of their organisations, rather than those of sociological and economic impact to the Australian populace. The author sees the need to examine the issue of mobile phone bills of teens and related matters as a follow up to Funston \& McNeill (1999), to compare the situation between then and now and to carry out a comprehensive quantitative and qualitative (textual) content analysis of media coverage of issues related to mobile phones and children in Australia from the critical theory perspective (Crotty, 1998), with respect to their discourses and framing to examine which discourses dominate and whose interests may be served in the process.

The author also sees the need to examine the potential and actual academic or formal educational uses of mobile phones and children in Australia using case studies -especially for distance education currently carried out with Internet related technologies such as WebCT or Blackboard, which link geographically dispersed individual and groups of students to work in collaboration with each other.

Another possible area for future study would be the in depth examination of actual and possible parental control with regard to mobile phone communication involving children and teens. 


\section{Acknowledgements:}

The author wishes to thank Ross Monaghan (Deakin University) and Andrew Funston (Victoria University) for their cooperation and useful insights provided when researching this topic and Ms Jo Gulli of the Corporate Citizenship Research Unit (CCRU) at Deakin University for the valuable research assistance provided.

\section{References}

AAP. (2006, November 11). Phone companies target six-year-olds. Retrieved on 21 November 2006 from http://www.theage.com.au/news/National/Phone comapanys target...

ABS. (2006). Population clock. The Australian Bureau of Statistics, Canberra. Retrieved on 1 December 2006 from http://www.abs.gov.au/Ausstats

Ace*Comm. (2005). Kids and mobile phones: How service providers need to address parental concerns. Vendor White Paper, November, p. 14.

ACMA. (2006). Аnnual Report 2005-2006. Australian Communications and Media Authority, Melbourne, VIC.

ACMASphere. (2006). New scheme to protect premium mobile content service users. Issue 14 (November), 3-4. Australian Communications and Media Authority, Melbourne, VIC.

Allison, S. (2004 December). Australia wins mobile phone race. Youth Studies Australia.

Australian Government to censor $3 \mathrm{G}$ mobile content. (2006, June 15). Wikinews. Retrieved on $28^{\text {th }}$ July 2006 from http://www.wikinews.org/wiki/Australian_govt_to_censor_3G_mobile_content

Australian Mobile Telecommunications Association [AMTA]. (2004). The impact of the mobile telephone in Australia: Social science research opportunities-A discussion paper. Australian Mobile Telecommunications Association, Melbourne, VIC.

Barker, G. (2006, December 2). Mobility goes well beyond the call. The Age, p. Business 2.

Beniger, J. R. (1986). The control revolution: Technological and economic origins of information society. Cambridge, MA: Harvard University Press.

Big Brother Australia. (2006). Wikipedia. Retrieved on 4 December 2006 from http://en.wikipedia.org/wiki/Big_Brother_Australia_Series 6)

Burns, A. (1981). The microchip: Appropriate or inappropriate technology? Chichester: Ellis Harwood.

Chapman, C. (2006). Regulating a dynamic mobile telecommunications industry. [Extract of speech to the Mobile Telecommunications Conference 2006.] ACMASphere, 13(October), 3-5.

Crotty, M. (1998). The foundations of social research: Meaning and perspectives in the research process. Sydney: Allen \& Unwin.

Croucher, J. S. (2006, December 2). Number crunch. The Age-Good Weekend Magazine, p. 13.

Dicken-Garcia, H. (1998). The Internet and continuing historical discourse. Journalism and Mass Communication Quarterly, 75 (Spring), 19-27.

Entman, R. M. (1993). Framing: Toward clarification of a fractured paradigm. Journal of Communication, 43(4), 51-58.

Foucault, M. (1977). Discipline and punish: The birth of a prison. (A Sheridan, Trans.) London: Alan Lane.

Funston, A., \& Hughes, K. (2006). Use and value of ICTs for separated families. Telecommunications Journal of Australia, 56(2), 76-85.

Funston, A., \& McNeill, K. (1999). Mobile matters: Young people and mobile phones. Melbourne, VIC: Communication Law Centre. 
Geser, H. (2004). Towards a sociological theory of the mobile phone. The University of Zurich, Zurich. Retrieved on $17^{\text {th }}$ August 2006 from http://socio.ch/mobile/t geser1.htm

Googin, G. (2006). Notes on the history of the mobile phone in Australia. Southern Review: Communication, Politics and Culture, 38(3), 4-22.

Goggin, G., \& Newell, C. (2000). Crippling competition: Critical reflections on disability and Australian telecommunications policy, Media International Australia-incorporating Culture \& Policy, 96, 83-93.

Hamelink, C. J. (1988). The technology gamble, informatics and public policy: A study of technological choice. Norwood, NJ: Ablex.

Handsley, E., Frost, L., \& Biggins, B. 2004. Submissions to the commonwealth Department of Communication, Information Technology and the Arts: Protecting consumers against illegal or offensive content on mobiles. September, Young Media Australia, Glenlg, SA.

Hirschheim, R. A. (1985). Office automation: A social and organizational perspective. New York: John Wiley.

Horstmanshof, L., \& Power, M. R. (2005). Mobile phones, SMS and relationships. Australian Journal of Communication, 32(1), 33-52.

Kinder, D. R., \& Sanders, L. M. (1996). Divided by color: Racial politics and democratic ideals. Chicago, IL: University of Chicago Press.

Lakoff, G., \& Johnson, M. (1980). Metaphors we live by. Chicago, IL: University of Chicago Press.

Langtry, B. (Ed.). (1998). All connected? Universal service in telecommunications. Melbourne, VIC: Melbourne University Press.

Levinson, P. (2004). Cell phone: The story of the world's most mobile medium and how it had transformed everything. New York: Pelgrave-Macmillan.

Marvin, C. (1988). When old technologies were new: Thinking about electric communication in the late $19^{\text {th }}$ century. New York: Oxford University Press.

McCombs, M. E., \& Shaw, D. L. (1972). The agenda setting function of the mass media. Public Opinion Quarterly, 36, 176-187.

McLuhan, M. (1969, March). Interview with Eric Norden: A candid conversation with the high priest of pop cult and metaphysician of media. Playboy, pp. 53-62, 64-66, 68, 70 72, 74, 148.

Media and society research project initiated. (2006). ACMASphere, 14(November), 5.

Melbourne teenage DVD controversy. (2006). Wikipedia. Retrieved on $4^{\text {th }}$ December 2006 from http://en.wikipedia.org/wiki/2006_melbourne teenage_DVD_controversy

Meyrowitz, J. (1985). No sense of place: The impact of electronic media on social behavior. New York: Oxford University Press.

Miletic, L. (2006, October 28). Technological trauma: Cyber bullies more powerful than schoolyard thugs. The Age, p. 6.

Miller, N. (2007, January 11). Apple pips the competition as it reinvents the phone. The Age, p. 3.

Moyal, A. (1984). Clear across Australia: A history of telecommunications. Melbourne, VIC: ThomasNelson.

Nielson/NetRatings. (2005). Australia's kids overtake their parents online. August 8 Media Release. Retrieved on $28^{\text {th }}$ July 2006 from http://www.nielsen-netratings.com

O'Riordan, A. (2005, November 21). Children studied for signs of mobile phone harm. The Guardian. Retrieved on $28^{\text {th }}$ July 2006 from http://www.mastaction.co.uk

Osbourne, P. (2006, June 14). Mobile phone porn jail term planned. The Australian. Retrieved on $28^{\text {th }}$ July 2006 from http://www.theaustralian.news.com.au 
Planalp. S. (1998). Current issues arising at the confluence of communication and emotion. Australian Journal of Communication, 25(3), 65-79.

Pressler, M. (2006, October 14). Cursives foiled again as writings on the wall. The Age, p. 18.

Reikert, M. (2006, July 13). Tune in, turn off. The Age-Green Guide, p. 10.

Richardson, T. (2006, March 27). Mobile cheats diddle exam system. The Register. Retrieved on $28^{\text {th }}$ July 2006 from http://www.theregister.co.uk/2006/03/27/mobile cheats/print.html

Solomon, W. S. (1992). News frames and media packages: Covering El Salvador. Critical Studies in Mass Communication, 9, 54-74.

Spiked-debate. (2006). Mobile phones and child protection: How far should we go? Spiked/O2, April. Retrieved on $28^{\text {th }}$ July 2006 from http://www.spiked-onlien.com/childprotection, April.

Stratel, A. (2006). TicTalk plans. Waurn Ponds, VIC: Telstra Shop. Retrieved on 26 October, 2006 from http://www.telstra.com/kidsintouch

Thomas, J. (2006). Editorial: Mobile histories. Southern Review: Communication, Politics and Culture, $38(3), 1-3$.

Topsfield, J. (2006, October 10). Bishop strikes at Victorian courses. The Age, p. 7.

Totally Mobile. (2006). Stuff Magazine, Issue 7. Melbourne, VIC: Government of Victoria, Consumer Affairs Victoria.

Weerakkody, N. D. (1999). Media and the construction of public opinion about Affirmative Action, race and related issues: A case study of opinion expressed during the 1992 US Presidential campaign. Unpublished doctoral dissertation, Rutgers University, New Brunswick, NJ, USA.

Weerakkody, N. D. (2007a). Webcasting in Australia: "Pretty dead, really". In L. S. Ha \& R. J. Ganahl (Eds.). Webcasting business models worldwide (pp. 357-379). Mahwah, NJ: Lawrence Erlbaum Associates.

Weerakkody, N. D. (2007b). A 'mobile' technology and the broadband 'horse trade': An examination of webcasting in Australia. The International Journal of Leaning, 13(8), 45-60.

White, D. M. (1950). The gatekeeper: A study in the selection of news. Journalism Quarterly, 27(4), 383390.

Wickremage, E. P., (Writer) \& Weerakkody, N. D. (Director). (1986). The evolution of the Sinhala Script (Akshara puranaya). In N. D. Weerakkody (Producer), From the pages of time (Yugayen yugayata) [Television series episode]. Sri Lanka Rupavahini (TV) Corporation, Colombo 7.

\section{Biography}

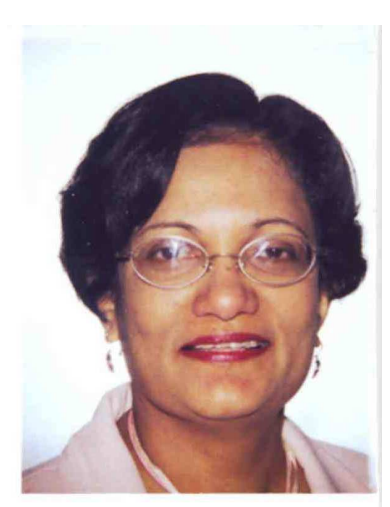

Niranjala Weerakkody ( $\mathrm{Ph} \mathrm{D}$, Rutgers U, NJ) is a Senior Lecturer in Media and Communication at Deakin University. Her other research interests on the adoption and diffusion of new communication technologies include digital TV (Australia \& USA), biometric devices (Australia, Malaysia and the USA), and webcasting (Australia). She currently teaches qualitative and quantitative research methods, media effects and organisational communication at both undergraduate and postgraduate levels. 